\title{
Argentina con China: el riesgo de la bonanza
}

\author{
Argentina with China: the risk of prosperity \\ Roberto Miranda *
}

\section{Resumen}

El objetivo de este trabajo es analizar las características del bilateralismo de Argentina con China, a fin de determinar la perspectiva de este bilateralismo como relación interdependiente. En este sentido, hipotetizamos que si bien Argentina obtuvo importantes «ganancias relativas», fue China quien amplió la asimetría preexistente en el marco de los extraordinarios niveles de interacción alcanzados entre ambos países. Esto significó, para Argentina, el riesgo de ingresar a una situación de dependencia con el país asiático. Precisamente en este análisis, más allá de haber realizado el recorrido de las relaciones bilaterales durante la primera década del presente siglo, identificamos los motivos y las condiciones que determinaron el mencionado riesgo.

Palabras Clave: Argentina- China- bilateralismo- interdependencia- riesgo

\section{Abstract}

The purpose of this paper is to analyse the characteristics of bilateralism between Argentina and China in order to determine the prospects of this bilateralism as an interdependent relationship. To this end we hypothesize that while Argentina obtained important relative earnings, it was China that widened the pre-existent asymmetry in the framework

\footnotetext{
Investigador del Consejo Nacional de Investigaciones Científicas y Técnicas (Argentina). Profesor de grado y post-grado en la Universidad Nacional de Rosario y Universidad Nacional de La Plata. robertoxmiranda@yahoo.com.ar. Recibido el 13 de mayo de 2014; aceptado el 21 de noviembre de 2014.
} 
of the extraordinary level of interaction reached between both countries. For Argentina, this involved the risk of entering into a situation of dependence with the Asian country. Beyond examining bilateral relations during the first decade of the present century, this paper identifies the reasons and conditions for the abovementioned risk.

KeYwords: Argentina- China- bilateralism- interdependence-risk 


\section{INTRODUCCIÓN}

En las relaciones internacionales de Argentina, así como en las de otros países latinoamericanos, Asia pasó a ocupar un lugar relevante en su política exterior. La demanda asiática de petróleo, cobre y soja, por mencionar los productos más destacados, facilitó un crecimiento económico impensable para América Latina en general y Sudamérica en especial, debido a las proporciones en que se dio tal crecimiento. Naturalmente, en todo este proceso China fue el actor internacional por excelencia, y en ella Argentina encontró un socio sumamente valioso, que no solo generó una realidad de intercambio comercial fructífero sino también grandes expectativas para el país sudamericano en otros aspectos de la relación.

El objetivo de este trabajo es analizar las características del bilateralismo de Argentina con China, a fin de determinar la perspectiva de este bilateralismo como relación interdependiente. Precisamente la asimetría entre ambos países se ha moldeado en la interdependencia a través de la cual dividieron ganancias relativas. Para Argentina este esquema ha sido enormemente beneficioso, sobre todo por la condición política y económica en que se encontraba el país a principios de siglo. Sin embargo, a lo largo del análisis, tendremos en cuenta una de las premisas fundamentales de Robert Keohane y Joseph Nye (1988: 23-25), al afirmar que solo existe interdependencia siempre y cuando en la interacción de efectos recíprocos uno de los actores no decline hacia una situación de dependencia.

\section{LAS MIRADAS SOBRE EL BILATERALISMO}

La mayoría de los estudios e investigaciones realizados en torno al impacto chino en América Latina coincide en que, como mercado, el país asiático ha sido una oportunidad que la región no ha desaprovechado. En este sentido, Ralf Leiteritz (2012:79) señala que entre China y América Latina se estableció una relación simbiótica de base económica. No obstante, un análisis más preciso revela que esa relación no ha sido homogénea para toda la región, porque en el vínculo con China, Argentina, Brasil y Chile fueron países «ganadores», mientras que en México y países centroamericanos se produjo más tensión que cooperación con Beijing. Más aún, el citado análisis subraya que el efecto da la relación con el país asiático fue porque el «aumento de las importaciones de China estuvo asociado a un aumento de las exportaciones a terceros mercados» (Montenegro, Pereira y Soloaga, 2011: 344, 360).

En lo que respecta a Argentina, cobró fuerza una percepción optimista sobre sus relaciones con China. Carlos Escudé (2011), a partir de su teoría de política exterior, destaca que en el realismo periférico de Argentina, el país asiático debería ocupar el lugar de Estados Unidos. Ello debido a que, 
por un lado, quedó demostrado que las economías de China y Argentina son complementarias, como en el caso de este país y Gran Bretaña en la segunda mitad del siglo diecinueve y en gran parte del pasado. Por el otro, porque Estados Unidos «muchas veces le propinó graves daños» a Argentina, lo cual -según Escudé- no ocurrió con China. Al mismo tiempo, se valora el efecto favorable que ha tenido el perfil de especialización de Argentina, a través del aumento de las cantidades exportadas a China más que por el precio, que le permitió al país «acumular superávit comerciales anuales del orden del $6 \%$ del PBI» (Bianco, Porta y Bismara, 2007: 141-143).

El perfil de especialización de Argentina condujo a que la dinámica de la relación bilateral se asentara particularmente en el aspecto comercial, al punto que China fue ocupando un lugar relevante en las exportaciones de Buenos Aires «a expensas del retroceso del Mercosur como mercado de destino" (Bouzas, 2009: 285). A propósito de esta realidad, se analiza que el interés argentino por una China compradora fue tan superlativo que incluso relegó a los países del sudeste asiático, pese al incremento de las ventas a estos (Rubiolo, Morero y Santillán, 2010:101-102). Pero el entusiasmo por China tuvo su costado inquietante.

En efecto, por un lado los ingresos de la soja, al no volcarse en una política industrial de cambio estructural para alejarse de la volatilidad de los precios de los productos primarios, mantuvo la vulnerabilidad externa como consecuencia de la «dependencia del mercado internacional» (Costantino, 2013: 9495). Por otro lado, porque China buscó «disciplinar» a Argentina mediante «la fuerza de atracción de su mercado para cambiar el comportamiento del gobierno", alineándolo en una relación típica del esquema Norte-Sur. De manera que Beijing ha utilizado «el mercado como fuente de poder, abriendo o cerrándolo frente a la reciprocidad de los actos de la contraparte, implementando una verdadera política de poder» (Oviedo, 2010:501).

\section{EL RIESGO}

No hay duda de que China ha sido absolutamente clave para que Argentina se reacomodara como país. Se convirtió en una alternativa cierta y fructífera, abriéndole márgenes de maniobrabilidad internacional, en circunstancias de que Argentina era un país encapsulado por Estados Unidos y Brasil. El vínculo con China, en lugar de ser una decisión autonomista, fue una oportunidad real para impulsar autonomía. Este concepto pareció estar presente en la política exterior argentina como consecuencia de las relaciones interdependientes con el país asiático. A través de estas relaciones se insinuó el fortalecimiento de la estrategia diversificadora de las relaciones exteriores, objetivo que Argentina por mucho tiempo trató de consolidar. Por otra parte, el gobierno creyó que había encontrado una fuente 
de financiamiento para el desarrollo, mientras padecía la penalización norteamericana en el acceso a la inversión por sus desobediencias económicas y políticas (Miranda, 2012).

En Argentina se suponía que la muy buena relación con China brindaría autonomía frente a otros actores, sobre todo ante las grandes potencias y los poderes transnacionales. Por cierto, la explosión exportadora fue un gran respaldo para el país en algunas cuestiones fundamentales que debió afrontar, por ejemplo, durante las negociaciones relativas al default. En otras palabras, Argentina no solo tuvo capacidad de decisión propia, sino que -aún más trascendental- pudo sostener lo decidido. Sin embargo, en la propia relación con China la autonomía estuvo en duda. La teoría nos dice que en una relación interdependiente la autonomía es proporcional a la reducción o conservación de la asimetría preexistente. Y precisamente, Argentina no pudo mantener el nivel de asimetría que tenía con China, por lo que el riesgo de ingresar en una situación de dependencia fue más que evidente.

\section{EL POSICIONAMIENTO ASIÁTICO}

Tras la crisis política y financiera que estalló en diciembre de 2001 y después de haber declarado el default más grande de su historia, Argentina logró una rápida recuperación económica. El $61.9 \%$ del PBI que representaba la deuda externa, así como la salida súbita del país de aproximadamente $15 \mathrm{mil}$ millones de dólares y los resabios de la recesión iniciada en 1998, no fueron obstáculo para que en el segundo y tercer trimestres de 2002 comenzara el crecimiento. Al respecto, la devaluación monetaria y el aumento de la demanda interna desempeñaron un papel más que importante $^{2}$. La reactivación económica puede atribuirse también a la producción de bienes no agrícolas, que representó alrededor del 19\% del $\mathrm{PBI}^{3}$. El signo negativo de $-10.9 \%$ del PBI de 2002 se revirtió al año siguiente, con un vertiginoso crecimiento que llegó al $8.8 \%$, y en 2005 , alcanzó al $9.2 \%$. La economía argentina fue justamente una de las que más creció entre 2003 y 2007 , con una tasa que estuvo por debajo de la de China, India y Venezuela pero por encima de la de Brasil, Chile, Indonesia, Malasia y México.

El auge exportador, que en un principio no fue espectacular, también tuvo mucho que ver con el restablecimiento de la economía, hasta lograr una expansión fundamental a partir del tercer trimestre de 2004. Pero el aumento de las exportaciones argentinas no fue casual. El incremento del comercio y de la producción que favoreció dicho aumento se debió a un cambio coyuntural

2 A esto, según Mark Weisbrot y Luis Sandoval (2007), se añade «el uso de una serie de políticas macroeconómicas heterodoxas».

3 Ver, Organización Mundial del Comercio, Acceso a los mercados para los productos no agrícolas, Comunicación de la Argentina, TN/MA/W/109/Rev.1, 6 de mayo de 2011. 
en el contexto internacional, como fue el desplazamiento del centro del poder y la riqueza mundiales del Atlántico hacia el Pacífico (Halliday, 2005). China, por Asia Oriental, e India, por el sur de Asia, fueron ejes principales del mencionado cambio que quebró las fronteras económicas de Occidente. Pero la cuestión no fue solo económica. Estados Unidos comenzó a ver claramente mermada su influencia en Asia pues -entre otras cosas- tuvo dificultades para adaptarse estratégicamente a la nueva realidad regional (Feigenbaum, 2011). Algo similar sucedió con Rusia, que no pudo coronar su independencia estratégica entre Occidente y Oriente a propósito del apogeo asiático (Kerr, 2010).

En la gran transformación geopolítica contrastaron la unipolaridad y la multipolaridad, como dos modelos opuestos de distribución del poder del sistema internacional (Miranda, 2012). Por un lado, se sostuvo que desde la caída del muro de Berlín, en 1989, hubo unipolaridad, gracias a la cual el mundo disfrutó de estabilidad y paz, pues según este enfoque, de lo contrario las guerras hubiesen sido una constante (Wohlforth, 2009; Krauthammer, 1990). Igualmente, se señaló que en el siglo XXI el citado modelo de poder no fue del todo consistente porque Estados Unidos perdió primacía económica y financiera (Layne, 2012). Sin embargo, se defendió la unipolaridad debido a que no hubo posibilidades de desafiar al hegemón y, además, porque ante la ausencia de un equilibrio de fuerzas, las perspectivas de multipolaridad eran nulas (Haass,
2008). De todas maneras, es interesante subrayar que, a partir de esta posición teórica, hacia fines del siglo pasado se vislumbró la configuración de tendencias polarizantes a través de Rusia, China e India (Binnendijk, 1999).

Justamente la novedad fue que esas tendencias polarizantes terminaron por moldear una multipolaridad. Para algunos analistas, China y Rusia fueron los principales promotores de esa creación a partir de su renacimiento como potencias luego de los roles principales que desempeñaron durante la Guerra Fría (Turner, 2009). En realidad, el resurgimiento de estos actores fue de índole económica, porque uno y otro ya contaban con el poder militar y nuclear obtenido durante la época de tensión Este-Oeste. Otros analistas, en cambio, entienden que las alianzas tejidas por China y Rusia con países medianos, para depender menos de Estados Unidos, fueron las que contribuyeron a formar la multipolaridad (Walt, 2009). De manera que este modelo de poder tuvo otros protagonistas fundamentales como India, Brasil, Indonesia, México y Sudáfrica, por citar algunos. Es probable que el multipolarismo económico haya sido la expresión más acabada del cambio coyuntural con el que tropezó Argentina, que trajo consigo un «sistema de desequilibrio estable» (Subacchi, 2008) basado en la prosperidad asiática en connivencia con algunas potencias regionales. 


\section{EL AUGE ABASTECEDOR}

En el primer y tercer trimestres de 2002 el comercio mundial recobró dinamismo y magnitud. Con el colapso de la tecnología de la información que había dominado en el decenio de los noventa, al introducirse máquinas y equipos relacionados con las telecomunicaciones, se produjo una modificación significativa en la distribución del comercio mundial de mercancías. La fuerte demanda de petróleo, cobre y soja activó ese comercio mediante las importaciones de los países de Asia Oriental y Estados Unidos, iniciando una etapa que sería esplendorosa en términos del intercambio de esos productos. El surgimiento de China como gran exportador e importador fue clave, al punto que este país sustituyó a Japón en el rango de mayor mercado asiático ${ }^{4}$.

A partir de 2003, el comercio internacional superó la tasa de producción y al año siguiente el aumento de las exportaciones mundiales de mercaderías se concentró en las de origen agrícola, las industrias extractivas y los metales. Lo distintivo de esta nueva etapa del siglo XXI no solo fue el incremento de los volúmenes exportables sino también el aumento de los precios de los bienes antes mencionados, que en el caso de la producción agrícola se relacionaban

4 Algunos analistas entienden que Japón dejó de preocuparse por el comercio como lo hiciera a partir de los años setenta del siglo pasado, y en su lugar puso la atención en objetivos geoestratégicos con el fin de equilibrar la influencia de China (Pyle, 2007). con el estancamiento de esta en América del Norte y Europa. La situación fue altamente beneficiosa para Argentina, como lo aseguró la Organización Mundial del Comercio en uno de sus informes, destacando que tal situación contribuyó a la recuperación de su PBI, y en 2007, al mejoramiento financiero de otros países latinoamericanos. Precisamente en 2006 el PBI de los países llamados emergentes representaba casi el $50 \%$ del total mundial, creciendo al $8 \%$ aproximadamente contra solo el $3 \%$ de las economías desarrolladas.

El alza de los precios de productos agrícolas, junto a los de las industrias extractivas, estuvo muy por encima de los precios correspondientes a los productos manufacturados. De manera que para Argentina, el incremento del comercio agrícola respecto del aumento del comercio manufacturero, fue un factor fundamental para sus exportaciones. Entre 2000 y 2007 el país fue el primer exportador de aceite de soja y tortas de soja. Lo significativo fue el crecimiento de la producción de estos bienes que en 2007 posicionaron a Argentina entre los 20 principales exportadores del mundo de productos alimentarios y agrícolas. Asimismo, ese año el país se ubicó en los primeros lugares entre los exportadores de soja y maíz, pues apareció como tercer vendedor de la oleaginosa después de Estados Unidos y Brasil, y como segundo del cereal, tras el hegemón.

En gran medida, desde 2002 hasta 2007 las exportaciones agrícolas le proporcionaron a Argentina un muy 
importante ingreso de divisas, que en total le permitió alcanzar ese último año a casi 60 mil millones de dólares. Por otro lado, cada año el saldo de la balanza comercial superó holgadamente los 10 mil millones de dólares. A pesar de que Argentina se potenció como país vendedor, su participación en el comercio mundial de mercancías no fue relevante. Durante esos seis años no varió el $0.4 \%$ de su participación en el total de las exportaciones mundiales, a diferencia de Brasil que del $0.9 \%$ en 2002 pasó al 1.2\% en 2007, ni superó su participación de $0.03 \%$ en el total de las exportaciones de servicios. Como se verá luego, en relación con el mundo y no con América Latina, entre 2000 y 2007 Argentina no pudo aumentar sus exportaciones de productos industriales, que siguieron representando alrededor del $30 \%$ del total de las ventas realizadas por el país al exterior, mientras que Brasil y México lograron que aumentaran estos productos en sus esquemas de comercio internacional respectivos, en el caso del primero a la mitad y en el del país del norte superando el $70 \%$.

El lazo entre lo que demandaba el comercio mundial y lo que podía brindar Argentina a través de su estructura productiva, fue uno de los motivos por los cuales los productos manufacturados no aumentaron su participación en las exportaciones del país. No obstante, esta realidad formó parte del desarrollo de las relaciones comerciales de Argentina, fundamentalmente de su diversificación de tales relaciones, lo cual fue una clara respuesta a las oportunidades que estaba ofreciendo el contexto internacional. Es muy significativo señalar que más que con la variedad de los productos vendidos esta diversificación comercial tuvo que ver con la ampliación de los destinos de las exportaciones. Argentina conservó la vieja relación con Europa a través de la cual canalizó las manufacturas de origen agropecuario (MOA). Entre 2008 y 2010 la Unión Europea fue el mayor mercado para las exportaciones argentinas de MOA, que representaron el 30\% del total de lo vendido por este concepto. Por otra parte, Argentina amplió sus mercados a través de América Latina y Asia. Respecto de la primera, Argentina exportaba manufacturas de origen industrial (MOI) a los países de la Asociación Latinoamericana de Integración (ALADI) que, entre otras cosas, implicaba una aproximación a lo que en este rubro vendía a Brasil para alcanzar la paridad en materia de destinos (Berrettoni y Polonsky, 2011).

El mercado latinoamericano fue el gran comprador de MOI de Argentina. Por ejemplo, en 2008, representó casi el $74 \%$ del total de las exportaciones de estas, pues nueve de los diez primeros países de destino de estas manufacturas eran de América Latina, con excepción de las de Estados Unidos, que ocuparon el tercer lugar. Como ya se señaló, Brasil fue el país comprador más importante de la región, ya que entre 2008 y 2010 figuró en casi el $40 \%$ del total de las exportaciones de MOI realizadas por Argentina. Muy lejos se situaban el 
segundo, que era Chile (8.95\%); el cuarto, Uruguay $(5.40 \%)$, y el quinto, México $(4.63 \%)$. No hay que perder de vista que la base de las exportaciones argentinas a Brasil fueron los productos de la industria automotriz que, en términos monetarios, en 2001 representó el $24 \%$ del total de todos los productos vendidos a este país y en 2009 alcanzó casi al $40 \%$, cifra ciertamente notable.

Aunque para Argentina las exportaciones de MOI al mercado latinoamericano no fueron suficientes para frenar su déficit comercial en este rubro, como tampoco para impedir que se redujera el superávit generado por la venta de productos primarios. En el seno de la OMC, Argentina reconoció que la balanza comercial de productos no agrícolas había "pasado de un superávit de 5.304 millones de dólares en el año 2002 a un déficit de 21.603 millones de dólares en el año $2010 »^{5}$. Justamente en 2008 la balanza comercial de MOI registró cifras rojas superiores a los 25 mil millones de dólares, y Brasil se convertía en una de las razones por las cuales aumentó el déficit de las exportaciones de manufacturas industriales. A estas corresponde en gran medida el saldo negativo de menos de 500 millones de dólares que comenzó a registrar Argentina a partir de 2003 en la balanza con Brasil, saldo que se elevó en los años siguientes llegando a un déficit de 3.524 millones de dólares en 2010. Esta realidad estuvo permanentemente en la agenda bilateral, a

5 Ver, Organización Mundial del Comercio, op.cit.. veces provocando tensiones y en otras generando una cooperación necesaria, pero fue sin duda una realidad que contribuyó a modificar la relación de Argentina con Brasil.

En vista de lo antes examinado, el hecho de que entre 2008 y 2010 Brasil y los países de la ALADI concentraran el $35.3 \%$ de las exportaciones argentinas no fue determinante del comercio exterior del país. En realidad, el factor determinante de ese comercio fue Asia. Si bien en ese período aquella región se ubicó en el segundo lugar de las exportaciones de Argentina, con el 19.1\% del total, representando una gran ampliación del mercado para sus ventas, lo significativo fue que colocó a muy altos precios lo que era el fuerte de su estructura productiva, es decir, los productos primarios, más específicamente la soja ${ }^{6}$. Así, Argentina aprovechó el cambio coyuntural, transformándose en un país proveedor de grandes volúmenes de mercancías de mucha cotización, y en este sentido tuvo en China a su principal cliente.

\section{EXPECTATIVA Y DESENCANTO}

A partir de 2003 el gobierno argentino priorizó la relación con Asia en general y con China en especial. Una de las acciones más importantes

6 «Si bien la evolución de la demanda mundial ha sido un importante factor de arrastre de las exportaciones argentinas, el desempeño de estas se vio también favorecido por la evolución del tipo de cambio» (Bianco y otros, 2007: 114). 
de política exterior fue la misión diplomática y comercial que encabezó el canciller Rafael Bielsa, cuando viajó a Beijing y Tokio hacia fines de aquel año. En China, además del valor de las conversaciones que entablaron sectores productivos y comerciales, estatales y privados de ambos países, lo destacable de la visita a Beijing fue la respuesta positiva brindada por el gobierno de $\mathrm{Hu}$ Jintao a los deseos argentinos ${ }^{7}$. Es cierto que China planteó su intención de realizar inversiones en Argentina, de ser socio bilateral en determinados sectores, como por ejemplo químico y plástico, y de invitar a Kirchner a visitar Beijing, pero también es cierto -vale subrayarlo por lo que sucedió a posteriori- que la viceministra de Comercio, Ma Xiuhong, reclamó la reducción del déficit en el intercambio, la eliminación de las barreras arancelarias a los productos originados en el país asiático y la facilitación de visas a empresarios de ese país.

El presidente argentino estuvo en China en junio de 2004, acompañado de una delegación de más de 250 empresarios. La visita fue oficialmente calificada de exitosa y Kirchner dijo que ella iba «a dejar grandes resultados», tal vez pensando en las posibles inversiones chinas en Argentina. Esto no lo mencionó el presidente $\mathrm{Hu}$, el cual sí calificó a Argentina como «socio

Vale comentar que en esa ocasión Bielsa percibió que, para Argentina, era mucho más importante China que Japón. Diario Clarín, «Bielsa: ahora hay que mirar a China», Bs.As., 5 de diciembre de 2003. importante para China en la región» y pieza valiosa en la cooperación que el país asiático quería tener con el Mercosur. La alusión al bloque no fue fortuita porque, un mes antes de la llegada de Kirchner, Hu había acordado rápidamente con Lula la formación de una coalición estratégica entre ambos países cuando este lo visitó, teniendo en cuenta que el presidente brasileño -en su gira de 2003- había firmado numerosos convenios con India. Además del papel que podía cumplir Argentina en la aproximación de China al Mercosur y de un mayor intercambio en todos los niveles, Hu pidió a Kirchner que se comprometiera a que ambos países establecieran una consulta permanente respecto de su participación en foros multilaterales, como las Naciones Unidas y la OMC.

Obviamente, los dichos de uno y otro presidente se vinculaban con los intereses que cada país tenía respecto de la relación bilateral, es decir, con lo que pretendían obtener de ella. El gobierno argentino perseguía superar la condición agroexportadora del país mediante el ingreso al mercado chino de productos con valor agregado, lo cual tendía a satisfacer uno de los anhelos de Kirchner, que era consumar la re-industrialización. En Shanghái, el presidente argentino vio la posibilidad de «una complementación comercial importante» mediante las MOA y las MOI, de ahí el número y la composición del grupo de empresarios que llevó a China, justamente ligados a esas actividades productivas. Más aún, la propia Cámara Argentino-China creyó que el 
aumento de las exportaciones llevaría a diversificar los productos exportados, como medicamentos, válvulas para motores, vinos, utilitarios y hasta la provisión de reactores y equipos del INVAP. Por otra parte, el gobierno argentino también buscaba desarrollar de manera conjunta la industria informática.

Los objetivos chinos en la relación bilateral no coincidían con los argentinos. Beijing buscaba abastecerse del mundo en materias primas, energía y alimentos, y algunas de las inversiones que en ese momento había realizado en el exterior, estuvieron dirigidas a los países que le proveían de gas, hierro, cobre y petróleo. No estaba en sus propósitos la compra de manufacturas argentinas, ni invertir en infraestructura en ese país. Recién en 2009 hizo las principales inversiones en infraestructura en América Latina - obras hidroeléctricas en Ecuador- y un año después, tanto en Brasil para la distribución de electricidad como en Venezuela para la construcción de una central termoeléctrica a gas. A China le interesaba insertarse en Sudamérica y afianzar el vínculo con el Mercosur a través de Brasil y Argentina, principalmente por el peso económico y demográfico del bloque, que en ese momento gozaba de una aceptable consideración internacional. Al mismo tiempo, Argentina, como país mediano, formaba parte de la suma que diplomáticamente hacía China para obtener apoyos en distintas instituciones internacionales, a través de las cuales había decidido librar batalla ante Occidente, con el fin de consagrarse en el nivel de gran potencia y en uno de los primordiales jugadores globales.

La gira de $\mathrm{Hu}$ por América Latina hacia fines de 2004 respondió a esos objetivos. Si bien es cierto que China demandaba materias primas, también lo es que percibió a la región como un mercado relevante para colocar sus productos manufacturados, algunos de ellos dotados de tecnología media. Esta colocación tenía la ventaja de que los productos manufacturados eran elaborados a bajos e incluso muy bajos costos. Sin embargo, el mayor interés de Beijing consistía en que países como Argentina, Brasil y Chile declararan que China era una economía de mercado. Precisamente con esta declaración el gobierno chino buscaba reducir la aplicación de medidas antidumping que podían frenar las importaciones de productos suyos cuyas ventas se hicieran por debajo del costo, o bien a un precio menor al de su propio mercado. De manera que mediante la declaración con estos países, China abandonaba la categoría de régimen de economía en transición asignada por la OMC hasta 2016 y pasaba a ser uno más de la organización para cubrirse de las acusaciones de dumping.

Una vez que Argentina, emulando a Brasil, firmó con China el memorando de entendimiento en el cual reconoció a este país el estatuto de economía de mercado y declaró «su decisión de no aplicar ningún trato discriminatorio a las importaciones provenientes» del mismo, la visita de $\mathrm{Hu}$ a Buenos Aires 
adquirió un sentido diferente del que había generado hasta ese momento, pues automáticamente se paralizaron las negociaciones sobre otros temas. Aunque Kirchner y Hu hablaron de sociedad estratégica, solo firmaron cinco acuerdos de modalidad marco vinculados a la cooperación espacial, turismo, ferrocarril, educación y cooperación económica y comercial. Fue el presidente chino el que definió la relación bilateral y lo hizo a través de cuatro ejes: i) cooperación económica, comercial y científica y técnica; ii) determinación de áreas de intercambio; iii) confianza política mutua; y iv) cooperación multilateral. Los últimos dos ejes reproducían lo que Hu le había pedido a Kirchner cuando este visitó Beijing, porque evidentemente eran claves en la estrategia global de la política exterior china.

Una de las escasas concesiones de China a Argentina luego de la firma del memorando, fue levantar las barreras fitosanitarias sobre carne vacuna y aviar y algunos productos agrícolas, algo similar a la cortesía que Hu había tenido con Lula ${ }^{8}$. De esta forma, tanto Argentina como Brasil podían exportar carnes al mercado chino. La apertura de este mercado para Argentina solo duró un año porque se produjo un

8 No obstante se sostuvo que «a cambio del reconocimiento brasileño, el gobierno chino prometió a Brasil negocios cercanos a los 1.000 millones de dólares por año, y la intención de invertir al menos 10 mil millones de dólares en Brasil» en dos años. $B B C$ Mundo, «Hu Jintao festeja en Brasil», 15 de noviembre de 2004. brote de aftosa en Corrientes. Pero la cuestión pasaba por otro lado, y era que el gobierno argentino se había formado grandes expectativas, como la posibilidad de inversiones chinas, cosa que no ocurrió, ya que solo hubo cartas de intención firmadas con empresarios asiáticos de acuerdo con el artículo cuarto del memorando citado, que estipulaba «el interés común en la promoción de inversiones». China, a través de Zhou Wenzhong, viceministro de Asuntos Exteriores, Yang Yang, director de la Oficina de Información del Consejo de Estado y Zhang Qiyue, vocera de la Cancillería, desmintieron categóricamente que su país invertiría 20 mil millones de dólares en Argentina, como pensaban el gobierno y algunos sectores privados?. Una cifra desproporcionada, considerando que hasta ese momento Beijing había invertido en el mundo solo 35 mil millones de dólares, la mayor parte en Asia-Pacífico (Velloso y Mengucci, 2008:83).

$9 \quad$ En ese momento se hipotetizó que las inversiones se iban a concretar «en un plazo de 5 a 10 años, no como desembolso único sino como inversiones en diferentes sectores»(Oliva, 2005: 224-225). Precisamente se especuló que las inversiones chinas iban a estar destinadas a los sectores pesquero, electrónico, telecomunicaciones, servicios y minero, pero hacia fines de la primera década del presente siglo, tales inversiones estaban "muy lejos de las cifras esperadas» (Cesarín, 2010: 8). 


\section{Agenda COMplicada}

Finalmente, se fue afianzando la complementariedad comercial de que había hablado Kirchner en Shanghái, pero no en los términos pensados por el presidente argentino. Los productos manufacturados no ingresaron al mercado del país asiático como se creyó que podía suceder. Precisamente las exportaciones de MOI de Argentina hacia China solo representaron el $1 \%$ del total de ventas de ese rubro en 2005-2006, cuando en 1992-1993 había sido del $2 \%$. El recorrido de esas exportaciones en el período 2003-2006 lo reflejó claramente; «de hecho, resultó ser el único destino hacia el que las ventas externas de MOI cayeron en términos absolutos, -17\%» (Bianco y otros, 2007: 125). Vale tener en cuenta -por otra parte- que en 2011 la participación de China en las exportaciones de MOI solo fue del $0.7 \%$ del total de lo vendido por Argentina en ese rubro ${ }^{10}$.

El embajador de China acreditado en Buenos Aires, Zhang Tuo, trató de disimular la realidad de la desigualdad del intercambio bilateral en virtud de la cual Argentina vendía materias primas y China exportaba manufacturas, diciendo que su país había importado valor agregado como los tubos de acero. Pero en verdad esta era la excepción a la regla, una excepción -por otra parte- que se caracterizó por ser de escasa magnitud. Los datos demostraban que

10 Ver, Asociación de Importadores y Exportadores de la República Argentina (2012: 19).
China no solo había logrado reducir el déficit en el intercambio comercial con Argentina, como lo había propuesto Ma Xiuhong en 2004, sino que con el tiempo había podido obtener superávit, lo que fue altamente preocupante para Buenos Aires.

El déficit comercial en las MOI se relacionó con el rojo de la balanza de Argentina con China. En un principio el país asiático fue gran demandante de «commodities de base agraria», pero sin dejar esa importante condición para las exportaciones argentinas se transformó en abastecedor de bienes industriales. Entre 2004 y 2008 las importaciones argentinas de productos chinos crecieron a un promedio anual del $69 \%$, principalmente por concepto de máquinas y aparatos (notebooks, monitores, partes de acondicionadores de aire y cámaras fotográficas digitales $)^{11}$. Por ello, a partir de 2008, el crecimiento del déficit comercial de Argentina con China no fue azaroso y en 2010 registró un saldo negativo de casi 2 mil millones de dólares, para aumentar al año siguiente a más de 4.500 millones de dólares. Es interesante considerar que Brasil, Chile, Perú y Venezuela fueron los únicos cuatro países de América Latina que no tuvieron déficit comercial con China. Los casos de Chile, Perú y Venezuela se explican por el bajo nivel de importaciones, debido a sus limitaciones en productos

11 Informe del Centro de Economía Internacional, Ministerio de Relaciones Exteriores y Culto, El comercio de la Argentina con China, julio 2009. 
con valor agregado y al consumo. En cambio, lo de Brasil ha sido sumamente excepcional, porque dada su estructura industrial y consumo logró un superávit de más de 11 mil millones de dólares (Cepal, 2012: 28).

La coyuntura internacional había convertido a Sudamérica en un inesperado exportador gracias al crecimiento indeterminado de Asia. En este contexto, a partir de 2007 , la complementariedad comercial que Argentina tuvo con China comenzó a transitar un camino diferente que, salvando las distancias y en un punto, se asemejó al de la época del vínculo que desarrolló a través de la alianza de poder con Gran Bretaña, a fines del siglo XIX (Sevares, 2007). Por un lado, se sostiene que «la complementariedad -vista desde China- articula una red de provisión de recursos naturales funcionales a su modernización, cuyo objetivo final consiste, además de proveer al bienestar de la población, en acotar las brechas asimétricas con Japón y Estados Unidos» (Oviedo, 2006: 398). Por otro lado, se afirma que aquella complementariedad ha tenido que ver con el "posicionamiento comercial» de China en el Mercosur "ante las 'insuficiencias' de la presencia estadounidense en la región» (Moneta, 2005: 198).

De esta forma, el país asiático, del sexto lugar que ocupaba en 2000 como destino de las exportaciones argentinas, pasó al segundo en 2011, gracias a la venta de productos del patrón de espe- cialización primaria ${ }^{12}$. En la estructura de comercio exterior de otros países latinoamericanos sucedió algo similar: en 2011 China ocupó el primer puesto en el destino de las exportaciones brasileñas (en 2000 se situó en el duodécimo), chilenas y peruanas, y el segundo lugar en las ventas venezolanas. China también escaló posiciones como proveedor de Argentina, del cuarto puesto en 2000 pasó al segundo en 2011, al igual que en las importaciones de Brasil, Chile, Perú y Venezuela, en todos los casos como abastecedor mayormente de productos manufacturados (Cepal, 2012: 31).

En este escenario, la tensión pasó a ser un elemento recurrente en la relación bilateral de Argentina con China, que se daba en un marco embarazoso para Buenos Aires, porque claramente estaba teniendo fuerte dependencia comercial de Beijing. China pasó a desempeñar el «papel de economía-mercado sostén para Argentina en función de la creciente demanda de materias primas» (Cesarín, 2010:10). Por otra parte, China había dividido a Argentina entre quienes ganaban por la forma en que se daba la relación bilateral y quienes perdían como consecuencia de tal relación, a lo que había que agregar el dilema del gobierno que, siendo el actor principal, debía interceder en torno a intereses opuestos. Entre los ganadores se contaban obviamente los sectores agrícolas y, sobre todo, en alto grado los exportadores de soja, por ejemplo, Cargill, Nidera, Bunge, Vicentín. Los

$12 \mathrm{Al}$ respecto ver, Marta Bekerman y Diego Cerdeiro (2007). 
perdedores incluían a aquellos que, en 2004, habían expresado al gobierno su temor por la invasión de productos chinos, a quienes en ese momento Kirchner tranquilizó con la consigna de que la industria nacional se encontraba protegida. A dos años de tal inquietud, para estos sectores productivos resultó un hecho que las importaciones de China podían comprometer la actividad económica, al punto que, en 2007, la Unión Industrial Argentina presionó al gobierno para que aplicara medidas restrictivas a estas importaciones.

El gobierno argentino no podía eludir la importancia de la venta de soja a China, cuya rentabilidad era una gran fuente de ingresos para el Estado a través de las retenciones. De manera que, más allá de cualquier forma en que se apreciara esta venta, para Argentina era imprescindible exportar la oleaginosa, a lo que hay que agregar que en su comercio exterior los envíos tanto de MOA como de MOI no podían equipararse con los de la soja. Esto era parte del dilema señalado más arriba, pues la otra era que el gobierno había asumido su desencanto por la inversión china que no llegaba a suelo argentino, pese a las cartas de intención firmadas en noviembre de 2004. Sobre todo, de acuerdo con lo analizado anteriormente, para ser más competitiva en el plano internacional en materia de productos manufacturados, Argentina necesitaba inversiones en infraestructura para modificar su patrón de especialización comercial. Hasta 2008 las inversiones chinas no superaron los 170 millones de dólares, y el país asiático no figuraba entre los veinte primeros inversores en Argentina.

La evolución del comercio bilateral le brindó a China un margen considerable para manejar la relación con Argentina de acuerdo con sus tiempos y propuestas, lo que fue importante para los intereses del país asiático. Para Argentina, el hecho de que ese comercio pasara de solo 250 millones de dólares en 1990 a casi 7 mil millones de dólares en 2006 constituyó un resultado ilusionante. Beijing supo aprovechar esta circunstancia, y con el tiempo, mientras Argentina obtenía réditos extraordinarios gracias a las exportaciones de soja mediante diferentes formas de producción, pudo convertirse en abastecedor de manufacturas, modificando a su favor -como señalamos más arriba- el saldo de la balanza comercial. Por otra parte, las propuestas de China se basaron en promesas debido al peso que tenían ante el entusiasmo argentino por las grandes ganancias que obtenía como proveedor agrícola. Así como el gobierno comunista reclamó una declaración que le reconociera el status de economía de mercado a cambio de inversiones futuras, en 2007 solicitó el apoyo argentino a su ingreso al Banco Interamericano de Desarrollo (BID) con el compromiso de que estudiaría la compra de títulos de deuda, acción que finalmente no llevó a cabo.

Las promesas del país asiático no pudieron evitar que Argentina resolviera restringir las importaciones de origen chino en 11 sectores, entre ellos 
neumáticos, textiles, juguetes y calzado, con el fin de proteger la industria nacional. A partir de esta decisión se inició una etapa de «efectos negativos» en la evolución del bilateralismo, según la denominación impuesta por el embajador chino en Buenos Aires, Zang Gang, en marzo de $2008^{13}$. La firma del convenio militar entre los ministerios de Defensa de ambos países, en mayo de 2007, no contribuyó a que se reencauzara el bilateralismo, pese a que se creyó que contribuiría a «fortalecer el concepto de relación estratégica» (Malena, 2010), en virtud del cual Argentina diversificaba la cartera de vendedores de equipamiento militar. Precisamente Beijing cumplió con la amenaza lanzada en 2005 de frenar la compra de soja si Argentina no respetaba la condición china de economía de mercado, y lo hizo aplicando rigurosos controles fitosanitarios al ingreso de la oleaginosa, sobre todo limitando el ingreso de aceite de soja. Para el gobierno oriental, al aplicar medidas antidumping y restrictivas a las importaciones de productos manufacturados chinos, Argentina desconoció lo dispuesto en el memorando de entendimiento de 2004, al contravenir la declaración del país asiático como economía de mercado.

Uno de los factores que influyó para que la tensión bilateral no pasara a mayores, fue la crisis financiera internacional originada en Estados Unidos a partir del tercer trimestre de 2008. Lo

13 Diario La Nación, "Queja china por las trabas a la importación», Bs.As., 11 de marzo de 2008. mismo puede decirse de algunas decisiones del gobierno chino relacionadas con América del Sur en general y Argentina en particular, que se destacaron por ser principalmente gestos amistosos. Una de ellas fue ofrecer al gobierno argentino un swap (intercambio) de monedas entre bancos centrales, tras haber descartado la compra de títulos de deuda como había insinuado en 2007. Este ofrecimiento, canalizado a través de un pre-acuerdo, se produjo en la asamblea anual del BID llevada a cabo en Medellín, en marzo de 2009. Consistió en que si Argentina necesitaba tomar en crédito alrededor de $10 \mathrm{mil}$ millones de dólares para hacer frente a una situación de iliquidez, o para afrontar la desventaja del peso ante la moneda norteamericana, entonces se le proporcionaría. Beijing había pactado esta práctica con Malasia, Corea del Sur e Indonesia, por citar algunos actores, pero Argentina fue el primer país latinoamericano en firmar un swap, que el gobierno calificaba de instrumento de contingencia.

Otra decisión china respecto de Argentina, fue cuando hacia fines de 2007 volvió a reconocerle a Argentina la condición de país libre de aftosa por vacunación, medida que permitió iniciar un proceso de negociación para el ingreso de carne argentina al mercado del Estado asiático. Pero lo más notorio fue que el gobierno chino reforzó este proceso con la firma, en noviembre de 2010, de un importante protocolo sanitario que significó la exportación de todo tipo de carne vacuna hacia el país 
oriental, como también de lácteos y cebada. Por otra parte, como ampliación de sus gestos, China forjó la firma de acuerdos bilaterales de índole sanitaria y de cooperación para aumentar sus compras de productos agroalimentarios, por ejemplo, de origen vitivinícola, cítricos y harinas de carne. Sin embargo, Argentina, como la mayoría de los países latinoamericanos, "no pudo diversificar sus ventas a China» (Oliva, 2008: 58). Justamente en 2010 casi el $70 \%$ del total de las exportaciones de la región al país oriental se basó en productos primarios, y un $20 \%$ aproximadamente en manufacturas basadas en recursos naturales, lo cual testimoniaba el fenómeno de la «reprimarización exportadora de América Latina y el Caribe» (Cepal, 2012:33).

\section{UNA RELACIÓN DISCRETA}

Entre 2003 y 2010 Argentina firmó 37 convenios con China, superado este número por los acuerdos concretados con España, Italia y Rusia en cuanto a países extra-regionales, lo cual fue una señal altamente positiva en el vínculo con Beijing. Sin embargo, la tensión continuó siendo el telón de fondo de las relaciones bilaterales. China prácticamente dejó de comprarle aceite de soja a Argentina porque eligió a Brasil como proveedor de ese producto, en el marco en el cual este país, durante diez años, se había convertido en su principal socio comercial. Evidentemente, la coalición estratégica entre
Brasil y China se profundizó, por sus respectivos poderes duros y por compartir como actores globales y líderes regionales posiciones comunes en foros económicos multilaterales.

Las diferencias comerciales entre ambos países, algunas muy similares a las de Argentina con China, por ejemplo, en el tema de las importaciones de manufacturas asiáticas, fueron rebasadas por las necesidades de Beijing de encontrar en Brasil un abastecedor seguro de materias primas, principalmente de petróleo y hierro, para lo cual decidió realizar en el país sudamericano inversiones en infraestructura ligadas a la industria extractiva. Con Brasil, que ha sido el principal destino latinoamericano de sus inversiones, China puso en práctica su política de financiar el sostenimiento de la producción de lo que compra. Según la Cepal, a partir de 2010 "China ha pasado de ser un inversionista marginal de América Latina y el Caribe a tener una presencia importante en numerosos países e industrias de la región» (Cepal, 2011: 131). Al respecto, sus objetivos respecto de Brasil quedaron de manifiesto en la Segunda Cumbre de países BRIC (Brasil, Rusia, India, China), organizada en abril de 2010 en San Pablo.

En el caso de Argentina, la situación fue diferente. El gobierno chino desplegó un discurso de malestar a propósito de las medidas proteccionistas implementadas por Argentina mediante las licencias no automáticas. Algunos funcionarios asiáticos como Yang Shidi, consejero Económico y Comercial de 
la embajada china en Buenos Aires, se refirió tanto a la injusticia del proceder argentino como al incumplimiento de lo firmado por Kirchner y Hu. Pero lo más importante fue que sostuvo que el gobierno argentino se apartaba de las reglas de la $\mathrm{OMC}^{14}$. En esta misma línea de cuestionamiento, Wang Junten, director general del Centro de Comercio Internacional de China, de visita por Buenos Aires en 2009, amplió la crítica, subrayando que si bien su país quería fomentar el bilateralismo, porque representaba «la tendencia mundial de la globalización", no era "adecuado imponer límites» a tal tendencia. Un año después, el viceministro de Comercio, Jiang Yaoping, caratuló a las medidas argentinas de «extremadamente anormales y discriminatorias». Sin embargo, Argentina no estuvo sola en la aplicación de medidas distorsivas contra China, porque Brasil, India y Rusia también lo hicieron y en un número importante, pero como los intereses de Beijing con estos países tenían un peso distinto, la actitud también fue diferente.

La distancia entre Argentina y China quedó de manifiesto cuando Cristina visitó el país asiático, en julio de 2010. De algún modo, tanto la Presidenta como Hu trataron de reinstalar el buen clima entre ambos países, luego de que en enero de ese año la mandataria cancelara su viaje a Beijing y de que el presidente chino excluyera a Argentina de su gira por Sudamérica, en el que visitó Brasil,

14 Diario La Nación, «Fuerte queja de China por las barreras a sus productos", Bs.As., 8 de marzo de 2009.
Chile y Venezuela. La cordialidad hizo que ambos jefes de Estado acordaran la formación de una comisión bilateral cuyo objetivo principal era tratar las controversias comerciales. Sin embargo, esta coincidencia protocolar, en realidad, tuvo por objeto encubrir lo que ambos gobiernos tenían en común, esto es, en un caso la negativa a comprar aceite de soja argentino y en otro levantar las restricciones a las importaciones de productos chinos. No obstante, como Beijing se vio obligado a aumentar sus importaciones de aceite de soja, debido a que no le bastó con el abastecimiento norteamericano y brasileño, recurrió al suministro argentino, aunque comprando un volumen reducido y dejando constancia de que se trataba de una contingencia.

Los intereses en la relación bilateral eran desproporcionados. La participación argentina en las exportaciones e importaciones de China, entre 2007 y 2010 , oscilaron entre el $0.4 \%$ y $0.5 \%$ del total del comercio exterior del país asiático, es decir, valores poco significativos para la visión estratégica que en esos momentos tenía el gobierno comunista. Al mismo tiempo, en la participación en las importaciones de China, Argentina no podía modificar la concentración de sus ventas en la soja y derivados, como ocurrió en 2010, cuyos montos llegaron casi al $80 \%$ del total de lo que exportaba a ese país ${ }^{15}$. Como

15 Ver, Ministerio de Economía y Finanzas Públicas, El Comercio Exterior Bilateral Argentina-China, documento de trabajo, agosto de 2011. 
los datos revelaban que la intensidad de la interacción entre ambos países, en comparación con las cifras registradas en el siglo pasado y por la forma en que se configuraba el intercambio comercial, desde el punto de vista cualitativo, era dispar. Por ello, la tensión y cierta inercia que por momentos dominó las relaciones bilaterales, pusieron en claro que su fluidez dependía de las circunstancias y que Argentina carecía de una política estructurada para conducir el vínculo con el país asiático.

China percibió a Argentina como un país de commodities, más concretamente como una potencia agrícola, y eso fue lo que le interesó de la relación bilateral. Pero Argentina no le era relevante. En 2010, de los 20 primeros productos que importó, del reino vegetal solo figuraron los porotos de soja, con el 1,8\% del total de lo comprado al mundo por el país oriental, y su principal proveedor fue Estados Unidos, cuyas ventas abarcaron casi el $50 \%$ de los envíos ${ }^{16}$. Por otra parte, Argentina se ubicaba en el trigésimo segundo lugar como país de origen de sus importaciones. La realidad de que Argentina no le era relevante, fue uno de los motivos por los cuales China no se esforzó en que prosperara una eventual coalición estratégica como lo hizo con Brasil, combinando política y comercio, movida esta alianza a través de necesidades comunes.

Para Beijing, la bonanza que lograba Argentina, a través de la exportación

16 En el período 2006-2010, los productos del reino vegetal representaron el $2 \%$ del total de las importaciones chinas. de soja y derivados, era suficiente para que el país fuera compañía política en algunas instancias multilaterales y en la puja entre Occidente y las potencias regionales que jugaban globalmente. Además, junto con Brasil le garantizaba la interlocución con el Mercosur, bloque que apreciaba en las nuevas relaciones de poder mundial. No le interesó realmente otra cuestión de Argentina, al menos en el primer decenio del presente siglo. Prueba de ello es el tema de las inversiones. En 2010, por ejemplo, Beijing anunció nueve operaciones en América Latina por más de 22 mil millones de dólares, destinados a la extracción de metales (cobre y hierro) y petróleo, industria del acero, automotriz e instalación de redes eléctricas de alta tensión ${ }^{17}$. De esas nueve operaciones, siete se centraron en Brasil, por un total cercano a los 10 mil millones de dólares, una en Chile y la última fue la compra que hizo la empresa estatal de petróleo CNOOC del 50\% de Bridas Corporation (Grupo Bulgheroni) por 3.100 millones de dólares ${ }^{18}$.

17 Ver, «¿Dónde y cómo invierte China en América Latina?: el informe de la Cepal», 16 de mayo de 2011. Recuperado el 26 de noviembre de 2013 de: http://asiapacifico. bcn.cl/noticias. "Comercio sino-latinoamericano se recupera con desafíos para un desarrollo sostenible», 29 de diciembre de 2010. Recuperado el 26 de noviembre de 2013 de: http://spanish.newa.cn/especiales. Diario La Nación, «Por fin llegan las inversiones chinas», Bs.As., 31 de octubre de 2010.

18 También se ha contabilizado, en 2010, la compra del $100 \%$ de Occidental Argentina, que pertenecía a Oxy de Estados 
Argentina sobreestimó a China. Después de cinco años consecutivos de superávit en la balanza comercial, que osciló entre 400 y casi 2 mil millones de dólares, el país asiático apareció como otra de las alternativas posibles para reducir la dependencia de Estados Unidos y Brasil, vinculada una con el acceso a la inversión transnacional y la otra con el comercio. Sin embargo tal alternativa no tuvo la preeminencia que se esperaba. Buenos Aires creyó que iba a diversificar las compras de productos argentinos, como en 2010 lo reclamó la ministra de Industria Débora Giorgi, y no fue así. Solo obtuvo del gobierno comunista respuestas aisladas y a veces dilatorias. Es más, el gobierno argentino no imaginó que China se transformaría en un serio competidor con productos de valor agregado. Es posible que el estilo de poder blando que adoptó el país oriental para su "comunismo de mercado", opuesto a las prácticas del «aventurismo norteamericano», haya sido una señal que atrajo al gobierno argentino (Bailes, 2009).

Pero el crecimiento chino implicaba otra cosa. El país asiático se encontraba muy comprometido con el fortalecimiento de su poder duro, por ello su política de inversión en territorio

Unidos, por parte de SINOPEC, en 2.450 millones de dólares. Por ello se señala que en ese año las inversiones confirmadas por China orientadas a Argentina alcanzaron los 5.550 millones de dólares. Para 2011 se anunciaron casi 10 mil millones de dólares de inversión en Brasil, casi 9 mil millones en Perú y 3.530 millones en Argentina (Cepal, 2011: 111 y 120). argentino fue extremadamente tibia, y la mayor contrariedad consistía en que ella no apuntaba hacia lo que perseguía el gobierno kirchnerista. Beijing, al priorizar determinadas estrategias para su desarrollo y capacidad productiva, impulsaba inversiones en cuestiones vinculadas al uso de la tierra, la comercialización de minerales y la participación en el transporte de carga, en circunstancias de que Argentina prefería que el capital extranjero se volcara hacia la reindustrialización del país.

Precisamente en 2003 la ilusión argentina sobre las posibles inversiones chinas habían pasado por la aeronavegación espacial, la siderurgia y la biotecnología, por citar algunas que con los años no materializaron, en cambio sí existió capital chino del grupo A Grade Trading para reactivar por casi 30 millones de dólares la mina de hierro de Sierra Grande (Río Negro), paralizada desde 1992 por la disolución de HIPASAM (Hierro Patagónico Sociedad Anónima Minera) ${ }^{19}$. La falta de respuesta de China a lo que ambicionaba Argentina para una mejor evolución de las relaciones bilaterales, confirmó que la asimetría de la interdependencia se había ensanchado en favor del país asiático.

\footnotetext{
19 De todas maneras se sostiene que «las inversiones en recursos naturales han sido también escasas, contrariamente a lo que debería esperarse por el concepto de complementariedad económica» (Velloso y Mengucci, 2008: 88).
} 


\section{Conclusión}

La relación de Argentina con China, durante la primera década del presente siglo, alcanzó niveles de interacción que en otros momentos fueron absolutamente impensables. La demanda sojera impulsada por Beijing activó varios circuitos del bilateralismo, como los vínculos políticos, militares y culturales. Así se estableció una relación interdependiente fecunda, obviamente impulsada por el desarrollo chino. Sin embargo, el citado bilateralismo fue espasmódico, pues fluctuó entre demostraciones de amistad y etapas de fricción. Estas etapas pusieron de manifiesto cuán lejos llegaron los efectos del poder asiático que, por ejemplo, provocaron en Argentina reacciones para salvaguardar sus manufacturas. De esta forma la interdependencia, inaugurada a través de la riqueza comercial, se fue desnaturalizando como esquema de vinculación, en la medida en que la relación se fue tornando demasiado desigual para Argentina.

El riesgo de Argentina de ingresar en una situación de dependencia fue más que evidente. En el marco de la diversificación de los destinos comerciales, en lo que respecta a China no pudo diversificar sus productos con valor agregado e intensidad tecnológica. De este modo el país asiático no fue la opción esperada para iniciar el cambio de patrón de especialización primaria y ponderar el desarrollo interno. China planteó la relación como cualquier país capitalista del Norte con objetivos de maximización del poder, típicos de un actor que busca competir en la lógica de los poderosos. Por ello buscó la complementariedad con criterio de contingencia y le dio a la dinámica comercial una amplia cobertura política, que consistió en circunscribir la relación con Argentina a un molde de necesidades comunes más que de intereses comunes. En este punto dejaba parcialmente satisfecha a Argentina y no se comprometía con cuestiones ajenas a sus urgencias.

La negativa a comprar volúmenes importantes de productos con valor agregado e intensidad tecnológica profundizó la distancia estructural entre ambos países, a la cual se añadió la muy escasa inversión china en Argentina que, además, se orientó hacia productos no renovables indispensables para el progreso económico del país asiático. Tal vez este fue el golpe más duro para el gobierno argentino, que buscaba afanosamente fuentes de financiamiento e inversión ante la indiferencia del mercado tradicional. Por otra parte, China no distribuía solidaridad, porque en el exterior no invertía para la realidad de los demás sino para la suya propia. Por cierto que en China Argentina encontró un factor para su recuperación económica, una suerte de asimetría benévola. Enhebró una fluida interdependencia vinculando cuestiones basadas en la interacción exportadora. Pero esa asimetría, cada vez más amplia, fue tomando color de subordinación a las políticas de Beijing. 


\section{REFERENCIAS BIBLIOGRÁFICAS}

Asociación de Importadores y Exportadores de la República Argentina (2012). Análisis del comercio exterior argentino en 2011. Reflexiones para favorecer la producción nacional.

Bailes, Alyson (2009). «El mundo en los últimos veinte años: tendencias y evolución». En Anuario Internacional CIDOB 2009, pp. 13-22.

Bekerman, Marta y Diego Cerdeiro (2007). "Crisis y patrón de especialización comercial en economías emergentes. El caso de Argentina», En: Problemas del Desarrollo. Revista Latinoamericana de Economía, vol. 38, n¹50, pp. 133-165.

Berrettoni, Daniel y Mariángeles Polonsky (2011). «Evolución del comercio exterior argentino en la última década: origen, destino y composición». En: Revista del CEI, Ministerio de Relaciones Exteriores y Culto, n¹9, pp. 81-99.

Bianco, Carlos, Fernando Porta y Felipe Vismara (2007). "Evolución reciente de la balanza comercial argentina. El desplazamiento de la restricción externa». En: Autores Varios, Crisis, recuperación y nuevos dilemas. La economía argentina 2002-2007. CEPAL-Colección de Documentos de proyectos, pp.107-148.

Binnendijk, Hans (1999). «Back to Bipolarity?». En: The Washington Quarterly, vol. 22, nº 4 , pp. 7-14.

Bouzas, Roberto (2009). «China y Argentina: relaciones económicas bilaterales e interacciones globales». En: Autores Varios, China-Latinoamérica: una visión sobre el nuevo papel de China en la región. Instituto de Investigaciones Jurídicas, UNAM, pp. 283-301.

CEPAL (2011). La inversión extranjera directa en América Latina y el Caribe 2010.

CEPAL (2012). La República Popular China y América Latina y el Caribe. Diálogo y cooperación ante los nuevos desafios de la economía global.

Cesarín, Sergio (2010). China y Argentina: enfoques y recomendaciones de politica para potenciar la relación bilateral. Fundación Ebert.

Costantino, Agostina (2013). "¿Gatopardismo sojero? Los efectos de la bonanza sojera sobre el cambio estructural de Argentina y Brasil». En: Nueva Sociedad, n²44, pp. 84-96.

Escudé, Carlos (2011). China y la inserción internacional de Argentina. Universidad del CEMA, Documento de Trabajo ${ }^{\circ} 462$.

Feigenbaum, Evan (2011). "Why America No Longer Gets Asia». En: The Washington Quarterly, vol. 34, n², pp. 25-43.

Halliday, Fred (2005). «El siglo XXI toma forma: 2004, un año a tres velocidades». En: Anuario Internacional CIDOB 2004, pp. 13-20.

Haass, Richard (2008). «The Age of Nonpolarity. What Will Follow U.S. Dominance». En: Foreign Affairs, vol. 87, n³.

Keohane, Robert y Joseph Nye (1988). Poder $e$ interdependencia. Buenos Aires: Grupo Editor Latinoamericano.

Kerr, David (2010). "Central Asian and Russian perspectives on China's strategic emergence». En: International Affairs, vol. $86, \mathrm{n}^{\circ} 1$, pp. 127-152.

Krauthammer, Charles (1990). «The Unipolar Moment». En: Foreign Affairs, vol. 70, $n^{\circ} 1$, pp. 23-33.

Layne, Christopher (2012). «This Time It's Real: The End of Unipolarity and the Pax Americana». En: International Studies Quarterly, n56, pp. 203-213.

Leiteritz, Ralf (2012). «China and Latin America: A Marriage Made in Heaven?». En: Colombia Internacional, ${ }^{\circ} 75$, pp. 49-81.

Malena, Jorge (2010). "Las relaciones sinoargentinas 1972-2010: un análisis de su dimensión política», En: Seminario Estrategias de Relacionamiento con la República Popular China, Consejo Argentino para las Relaciones Internacionales. Recuperado de: http:/www.cari.org.ar/ pdf/mcsrt2.pdf

Miranda, Roberto (2012). «Bush-Obama y la continuidad de la sanción política a Argentina». En: Intellector, Centro de Estudos 
Roberto Miranda

Argentina con China: el riesgo de la bonanza

em Geopolítica e Relações Internacionais, Rio de Janeiro, nº 16 , pp. 11-30.

Miranda, Roberto (2012). "Argentina y la bipolaridad Estados Unidos-China: implicancias de un escenario posible». En Reflexión Política, vol. 14, n²8, pp.68-81.

Moneta, Carlos (2005). "China y el nuevo proceso de institucionalización de la integración en Asia del Pacífico: perspectivas para Argentina/Mercosur y América Latina». En: Autores Varios, China y América Latina: Nuevos enfoques sobre cooperación y desarrollo, ¿una segunda ruta de la seda? BID-INTAL, pp. 163-202.

Montenegro, Claudio, Mariana Pereira e Isidro Soloaga (2011). «El efecto de China en el comercio internacional de América Latina». En: Estudios de Economía, vol. $38, n^{\circ} 2$, pp. 341-368.

Oliva, Carla (2005). «Inversiones en América Latina: la inserción regional de China». En: Autores Varios, China y América Latina: Nuevos enfoques sobre cooperación $y$ desarrollo, ¿una segunda ruta de la seda? BID-INTAL, pp. 224-225.

Oliva, Carla (2008). «Las posibilidades de un desarrollo armónico». En: Res Diplomática, ISEN-Ministerio de Relaciones Exteriores, Comercio Internacional y Culto, 2da Época, $n^{\circ} 3$.

Oviedo, Eduardo (2006). «China: visión y práctica de sus llamadas relaciones estratégicas». En: Estudios de Asia y África, Colegio de México, vol. XLI, n³, pp. 385-404.

Oviedo, Eduardo (2010). Historia de las relaciones internacionales entre Argentina y China,1945-2010. Buenos Aires: Dunken.
Pyle, Kenneth (2007). Japan Rising: The Resurgence of Japanese Power and Purpose. Public Affairs.

Rubiolo, María Florencia, Hernán Morero y Gustavo Santillán (2010). «La política exterior argentina hacia el sudeste de Asia entre las presidencias de Carlos Menem y Néstor Kirchner desde una mirada constructivista». En: Portes. Revista Mexicana de Estudios sobre la Cuenca del Pacífico, vol. 4, n' 7, pp. 83-107.

Sevares, Julio (2007). «¿Cooperación Sur-Sur o dependencia a la vieja usanza? América Latina en el comercio internacional». En: Nueva Sociedad, $\mathrm{n}^{\circ} 207$, pp. 11-22.

Subacchi, Paola (2008). «New power centres and new power brokers: are they shaping a new economic order?». En: International Affairs, vol. 84, n³, pp. 485-498.

Turner, Susan (2009). "Russia, China and a Multipolar World Order: The Danger in the Undefined». En: Asian Perspective, vol. 33, nº1, pp. 159-184.

Velloso, Miguel y Darío Mengucci (2008). «La rápida globalización china y las oportunidades que nos ofrece». En: Temas de politica exterior, comercio y relaciones internacionales, APCPSEN, Buenos Aires, $\mathrm{n}^{\mathrm{o}} 1$.

Walt, Stephen (2009). "Alliances in a Unipolar World». En: World Politics, vol. 61, n ${ }^{\circ} 1$, pp. 84-118.

Weisbrot, Mark y Luis Sandoval (2007). La recuperación económica argentina. Politicas y resultados. Center for Economic and Policy Research.

Wohlforth, William (2009). «Unipolarity, Status Competition, and Great Power War». En: World Politics, vol. 61, n¹, pp. 26-55. 